\title{
MEDIATION - A KEY INSTRUMENT IN THE INTERNATIONAL ARCHITECTURE FOR THE PEACEFUL RESOLUTION OF POSSIBLE CONFLICTS IN THE FUTURE
}

\author{
Elena Simion ${ }^{1}$ \\ "Carol I" National Defence University
}

\begin{abstract}
The role of mediation, in the current context of the security environment, involves the implementation of mediation techniques aimed at an integrated operational and efficient approach, depending on the development level and the requirements of the society, adapting the regulations of the mediation field, in accordance with the local specificities of each state, based on the broad consensus of the society.
\end{abstract}

Keywords: mediation; international relations; security environment; integrated approach.

\section{INTRODUCTION - BRIEF HISTORY}

The current international security environment can be defined as an atypical one, particularly difficult to be anticipated, given that the dangers, threats, risks and vulnerabilities require concerted action in order to eliminate the sources of conflict and violence between state and non-state actors. The international community must promote the development of a culture of security and defense, based on the common values, ideals and interests of international society, in order to maintain world peace and security. Globalization, the increasing number of actors on the international stage and the higher degree of interdependencies, has generated reconfigurations of power relations in the international system, causing conflicts whose complexity has become more and more difficult to manage.

Under the circumstances, it is necessary to promote a global order, based on observing the rules of international law, aimed at ensuring the respect for human rights, sustainable development and efficient management of divergent situations, perceived differently by the states of the world, according to the national interests and needs, military and economic power, membership or nonmembership of an alliance.

On the other hand, humanity is currently undergoing a major test, with a negative impact, generated by the Covid-19 Pandemic, which has provoked social and economic emergencies, with major and inherent potential for conflicts. Those effective peaceful resolutions can be achieved through national and international recovery and resilience strategies that identify opportunities for amicable discussions between all decision-makers and lead to viable solutions. In carrying out these strategies, the efficiency and importance of the mediation procedure for the transparent resolution of the post-crisis problems generated by Covid-19 is indisputable, as I will detail below.

\section{VALUING THE IMPORTANCE OF MEDIATION AS A FACTOR FOR RESTORING COMMUNICATION}

Conflict is a component part of human nature, social relations, induced by genetic factors, by the social environment and the education that each individual receives. Consequently, a broad consensus in society - which can facilitate the implementation of laws in an equitable manner, so that all people can be partners in the state or institution to which they belong - varies in accordance with the degree of development of each society, depending on the economic, political and social priorities of each state.

\footnotetext{
${ }^{1}$ Corresponding author: elena.t7@yahoo.com
} 
The essential factor in economic growth and innovation in a state is the responsible and transparent engagement to implement decisions aiming at general well-being and economic prosperity. In this way, through well-structured partnerships, including those in the business field, which attract capital, management and innovation, people come together and productive services, jobs are provided, converging to strengthen international cooperation in the public and private sectors. „Generically called disputes, these contradictions of interests, legally substantiated or simply an expression of circumstantial claims, have often led to violent conflicts with disastrous consequences on the international balance." (Ghiba 2017,35)

The cooperation between States and the International Court of Justice, as an alternative instrument available to States in a dispute, obliged " first of all to seek a solution through negotiation, investigation, mediation, conciliation, arbitration, judicial settlement [...]. or by their own peaceful means "(Justice 1945) in accordance with art. 33 of the Charter, has important consequences on the way states envisage their commitments, representing a solid foundation of the rules-based international order. The ICJ is one of the most efficient judicial bodies for resolving international disputes, provided that the necessary competence and power are granted to it, since the consent of states, as the main feature of jurisdiction, generates many problems in this regard.

The special impact in ensuring global security by the International Court of Justice, the main judicial body of the United Nations, consists in resolving disputes with reference to violations of the rules of international law, effective in regulating legal relationships resulting for judgment and in preventing similar violations of rights, by way of the rules of conduct imposed on the disputing parties and on the basis of the principles set out in the decisions rendered.

The work programs of the International Court of Justice are also relevant for taking into consideration the factors which, rationally and in good faith, may relate to the conditions set out in art. 4 paragraph 1 of the Charter on the Admission of Members to the UN, according to which "Membership in the United Nations is open to all other peace-loving states which accept the obligations contained in the present Charter and, in the judgment of the Organization, are able and willing to carry out these obligations" (ONU 1945) Analyzing the de facto principle deriving from this article, it follows that there is a general legal obligation for all members of the United Nations to act as lovers of peace, the only major obligation of the entities that use them being to act in good faith in order to find a solution to put an end to the dispute, inclusively when the states have to consent to the jurisdiction of the ICJ.

To this end, mediation, as a formula for alternatively resolving, in good faith, political, economic, informational, cultural, educational and so on conflicts, arises many questions about the use of the term, as well as the practices to which it applies: is it a mediation, a conciliation or a negotiation, the procedure used by the above-mentioned entities in order to find a solution putting an end to the dispute?

Conceptually according to analysts in this field, mediation "can be defined as a voluntary, structured process, through which a mediator facilitates communication between the parties to a conflict, which allows them to take responsibility of finding a solution to the conflict between them" (Commission 2012,7).

Given that, in international conflicts and not only, mediation becomes institutionalized and tends to function in other forms of social organization, I believe that this procedure contributes both to the sustainability of an existing system and to generating a potential way for social change, where the necessity imposes it, in order to identify instruments conducive to dialogue, with the positive intention of helping the parties to find solutions, because "[.....] we must not be concerned with preventing the outbreak of conflicts, but with resolving them peacefully.. In other words, we are talking about rendering the conflicts civilized" (Ghiba 2015,7).

In the above mentioned context, the usefulness of mediation results from the celerity with which an agreement can be reached, versus the alternative of the resolution by the Court, and requires a permanent research and the identification of viable and effective methods of resolving disputes that punctually define their causes, before analyzing opportunities and solutions, that turn 
disputes into dialogue, generating discussions leading to the transformation of the differences of opinion, interests and needs into innovation.

"The complexity of the relationships outlined within the international community involves determining communication links that exceed the management of conflicts generated by a security environment with a rapid and constant pace of evolution, requiring the existence of innovative procedures, specific to mediation, which dwell on deeply the current phenomenon of conflict causes in order to prevent their recurrence, adapted to new security risks." (Simion 2020,5).

Given the current international crisis generated by the Covid-19 Pandemic, the implementation of increasingly professionalized mediation techniques, adapted to the new conflict context, must also take into account the cultural and social impact and differences. Their implementation, for an integrated operational and efficient approach, requires, depending on the level of development and requirements of the society, the adaptation of mediation regulations, according to the local specifics of each state, based on the broad consensus of society.

An important facilitating instrument of conflict resolution, in an evolutive manner, focused on democratic rules, is diplomacy, which includes effective mediation techniques, with major impact in resolving conflicts generated by ethnic polarization, climate change, social and economic tensions, precarious governance and cultural differences.

"Digital Diplomacy facilitates dialogue (between citizens of the world and the entire diplomatic corps, between diplomats and institutions from the accrediting countries), participation in events, understanding the challenges of world politics, sentiments of not feeling excluded from the events and decisions of foreign policy and, last but not least, a higher level of participatory democracy." (Bodoni 2016,9-16).

For a good harmonization of all these above-mentioned situations, generating conflict, diplomacy can revive international mediation, which is "an efficient and viable diplomatic procedure for resolving the dispute". (Constantin 2005,19). Given that it uses a variety of instruments, skills in the art of negotiation and mediation techniques, based on long expertise in this regard, it can contribute to the resolution and prevention of conflicts in the future, proving its usefulness, to act in a multicultural environment, with various actors, including civil society.

"Conflict is a motor of change. By a stretch of imagination, it can be transformed in a constructive way in order to ensure equity, progress and harmony or, on the contrary, exploited in a destructive way generating strong insecurity." (States-ECOWAS 2008,7).

In consideration of the above, it follows that the mediation procedure, based on transparency, amicable settlement and direct participation, in good faith, are vectors more important than ever in these times for strengthening democracy and international stability. Promoting open and transparent governments, while guaranteeing security, confidentiality and civil liberties, is a major challenge of our times. Altogether, I believe that flexibility, which has always been a hallmark of diplomacy, provides an instrument for communication and amicable settlement of conflicts, able to be adapted to new challenges, and it will be useful for both states and other new actors on the international scene. in their efforts to create a better world for the 21 st century.

The International humanitarian law is a "guardian" of the respect for human vulnerability and personal integrity, a shield against bloody challenges, for people not being directly involved in war, along with medical personnel from medical missions or prisoners of war. It is regrettable that the current Covid-19 pandemic has not contributed to the end of wars, and in these areals areas, governments can sometimes come up against difficulties implementing decisions helping to combat this virus. However, given that the obligations under international humanitarian law (mentioned below) concern exceptional circumstances for war-torn states, they should not be an impediment to the fight against Covid-19, on the contrary, they should have contributed to the improvement of COVID-19 response strategies.

Now, more than ever, given the increasing population vulnerabilities caused by the COVID-19 pandemic, the most important international bodies in this field must focus on respecting the application of the law and the responsibility for violating the rules of international humanitarian law, which implicitly aim at the protection of the person. 
"The Under-Secretary-General for Humanitarian Affairs, Mark Lowcock, declared: "COVID-19 has already turned life upside down in some of the richest countries in the world. It now reaches places where people live in war zones, not having easy access to clean water and soap, and having no hope for a hospital bed if they fall seriously ill." (OCHA 2020) In accordance with this, an integrated approach, taking into account the level of the imbalance caused by the pandemic, which also affects the financial dimension, whose evolution is directly determined by the decisions of international financing institutions, is absolutely necessary in the overall framework of the fulfillment of sustainable development goals (SDG), focusing on the humanitarian actions and the agenda for peace and sustainable development, in accordance too with the United Nations General Assembly Resolution $46 / 182$ of 1991, which "designed the blueprint for today's international humanitarian system, which tirelessly strives to provide life-saving assistance." (OCHA 2016, 46/182).

The shock of the Covid-19 pandemic has major implications for the policies and governance of many key actors, which require global action programmes. In this regard, the United Nations, N.G.O or important donors, which participate in the reconfiguration and preparation of effective instruments for the realization of S.D.G. (Sustainable Develpment Goals), must put the emphasis on the resistance to possible future pandemic shocks. These can be achieved through the emergency response of national governments and state authorities, transposed through short-term crisis management measures, as a humanitarian response. Long-term strategies are also needed to strengthen the humanitarian system, based on solutions focused on knowing the instruments related to identifying who and what to do, how and in what way, that is focused on concrete solutions, depending on the real and objective "on-site" availabilities".

"In March, United Nations Secretary-General Antonio Guterres appealed for a global ceasefire because of the Covid-19 pandemic, pleading for a halt to hostilities to create corridors for life-saving and to open precious windows for diplomacy." (Hinds 2020).

The way in which the actors from the humanitarian assistance domain or field or area, including humanitarian organizations and agencies, will be able to identify effective solutions to counteract the negative effects of the humanitarian sector, caused by the Covid-19 crisis, will influence the future of the humanitarian sector. In accordance with the provisions of the Protocol Additional I of 1977 to the Geneva Conventions of 1949 (Crucea Roșie 1977) and the commentary of 1987 on international armed conflicts, the permanent or temporary medical units are assigned exclusively for medical purposes Therefore, whether civilians or military, these units can, by preventing any disease. Including Covid-19, reduce the number of victims, this protection being of course possible if their destination is totally a medical one.

"As it results from the definition of the international humanitarian law, this branch of law has a customary character, and, in accordance with the provisions of art. 38 point 1 letter b) of the Statute of the International Court of Justice, the international custom, "as evidence of a general practice accepted as law", is a source of international law." (Ghiba M.-D.2017,25). Given the above-mentioned provisions, the effects of the pandemic, in order to integrate a humanitarian and emergency response, will reconfigure and reorganize important segments of the international humanitarian sector, with major impact on the lives of billions of people on the planet, which will redefine the future of the humanitarian area, leading to the establishment of new sources of international law.

The International Health Regulations (IHR) of 2005 (UE 2009) is the instrument by which the World Health Organization can implement states' responses to global pandemics, taking also into account the principles of international law enshrined in the Charter of the United Nations (Unite 2020) is the areal for the international humanitarian action. Therefore, given that international emergency situations aimed at public health have a recommendable and non-binding character, they will generate numerous international conflicts between states, states and international organizations, investor-state disputes and conflicts related to human rights, between states and individuals.

Article 43 of the IHR provides that "any state party affected by [an additional measure] may request the state party implementing such a measure to take counsel with it [...] [in order to find a mutually acceptable solution." (Red Cross 2009). The settlement of disputes concerning disputes from one state to another is not hindered by these consultations, as Article 56 of the IHR (CruceaRosie 
2009) provides for mechanisms to resolve them, which in the first instance may choose any peaceful means, but are not obliged to resolve the conflict. If these means fail, the involved countries may agree on referring the dispute to the Director-General of WHO or to the International Court of Arbitration, whose resolutions shall be of a recommendatory nature.

Although the IHR can provide, in a transparent and efficient way, viable guidance as global response to protect the world's population from pandemics, it is necessary to identify new improved strategies to discover and report in good time the outbreaks centres, new sources of financing for development and maintaining the health of the population, the effective inter-state exchange of information and technology that avoids damage and represents effective strategic mechanisms for monitoring and resolving conflicts and suppressing the pandemic.

\section{MEDIATION - THE AVATAR OF EFFICIENT COMMUNICATION OF THE $21^{\text {st }}$ CENTURY}

The rapidity and extension of the changes, which occurred at the beginning of 2020, in the current security environment, amid the Covid-19 pandemic, which changed life as we knew it, require a readjustment and modification of the social contract, focusing on the individual, on the connections between the individual and the organization and the correlation of the organization's objectives with those of the society. In a world currently based on new technology, which involved bold technological innovations and digital transformations, which dominated the conversations between people, paradoxically accentuated by the international pandemic element, Covid-19, human concerns were considered separate and inferior, even in conflict with technological advances, being particularly difficult to remain human in a world based on technology.

As society has been concerned with adapting its ways of working in response to the crisis, with the potential to create sustainable value for organizations, for their workforce and for the society in general, Covid-19 has shown that human activities are not separated by technological advances. On the contrary, not the technology generated conflict, but the digital divide between regions, urban and rural communities has been the great challenge "In fact, classroom seems to be the first place of mediation, the first space of speech organized by the teacher..." [...]" After all, time for deliberation and negotiation is still time"(Beillerot 2010).

This crisis represents a unique opportunity - given the current situation, burdened by crises and conflicts in all spheres of international life - to identify new instruments and practices (with a desire for connection and well-being at work), to manage the way people adapt and work in partnership with the available technology in order to cultivate their capabilities to high standards and to generate connections which can open a future way appropriate to fuel development and innovation, to return to work, by designing the future of labor, using the lessons and practices they identified during their accelerated response to this crisis.

COVID-19 placed at the center of organizations the issue of physical, mental and financial security. The stress and exhaustion that many individuals faced, determined by the fact that they had to fulfill their professional obligations staying at home, in parallel with their personal obligations and roles (as parents, for example), generated conflicts. In this way, pandemic caused discrepancies between the feeling of personal identity and belonging to community life. The disagreements created, as a result of people's attempt to transcend personal gain in relation to the common good, also led to significant economic discrepancies between different regions of the world.

Now is the time to encourage open dialogue and open practices, through mediation, to resolve these disputes, ensuring, through the principles governing the institution of mediation, both the respect for fundamental rights and the protection of individuals, in accordance with the European Convention on Human Rights and the relative jurisprudence ["The Convention establishes a catalog of civil and political rights (with the exception of property rights, economic rights and rights with social connotations - freedom of association, right to training, prohibition of forced labor' (Radu 2016,8)].

The mediation procedure facilitates dialogue, develops trust between the conflicting parties and opens the possibility of redefining work objectives, towards results instead of stricto sensu established activities. In this way, the possibility of people to live and perform socially and individually, 
at very high levels, in an effort to embrace reformulations and solutions, governed by the law of the people, which has the precedence over the authority of states, opens up. The hierarchy of ethical, deontological and moral norms, as a standard of conduct, often contested in case of a dispute, are the basis of the principles and actions of mediation techniques.

Moreover, it must be borne in mind that "some conflicts are now being treated as threats to international peace and security, even if two states are not fighting. Particularly when internal conflicts involve violations of universal norms, such as self-determination, human rights or democratic governance, concerted international actions - including the threat or use of force - are taken to prevent, end or resolve them" (Council 2021) the mediator's role as defender of the public interest, as well as its ability to effectively manage the disputes faced by citizens in their relations with the public administration, can help them, through mediation-specific techniques, to promote open government strategies and initiatives, by identifying the difficulties between citizens and the public administration, due to its role as an intermediary.

A direct consequence of the crisis generated by the current pandemic is the impossibility in some cases to resolve disputes between the parties "face to face", which reveals that the IT tool determines the effectiveness of current experiences of digitalization of mediation. Online mediation can set efficient and ambitious goals, based on the existence of Covid-19, as an alternative solution of communication for the parties to a conflict, but also for the case of court proceedings, in order to identify convenient, mutually beneficial solutions through methodological and technical tools specific to this alternative procedure, being an effective alternative to maintain social connections and resolve disputes quickly, where possible. This procedure requires, of course, a material basis for achieving the flow of information, $\mathrm{Hi}-\mathrm{Tech}$, at high technological standards which characterize the digital system.

"[...] as an observer of the legal profession community, I predicted that alternative methods of dispute resolution (ADR) would be one of the major axes for transforming the practice of law. However, our predictions lacked a health crisis and two months in detention, which made them essential to ease the jurisdictions that passed from "crowded" to "suffocated". Another imperative was born from this health crisis: that is to promote social distance. In this context, dematerialized platforms for resolving disputes amicably become a tool of choice." (Hantz 2020).

Furthermore, online mediation does not lead to a deprivation of rights, such as a lawsuit. On the contrary, the freedom of action of mediation procedures, the flexibility granted by the status of the mediator, are an effective, fast and safe dispute management tool, including in terms of protecting the health of the parties to the conflict, thus respecting the rules of physical distance due to the pandemic, with the role of solving the disputed problems with maximum efficiency and rapidity, in many situations, while respecting the security of the global health of the population.

\section{CONCLUSIONS}

The basic criteria of Maslow's hierarchy of needs still guide what people want and how they order their preferences, so that building a sustainable post-Covid future focuses on the need to approach the ethical issues of access to data related to future-oriented workforce and requalification, involving investments in work for an uncertain future. As the return to work takes place, organizations have the opportunity to build a culture of action that will transform the way of approaching the organization's resilience and create strategies that strengthen the organizational connectivity and provide solutions in order to resist and even to prosper in environments of perturbation, conflict, uncertainty and change.

The moments of crisis during the COVID-19 pandemic, together with the conflicts generated by unstable governments, socio-economic and ethnic tensions, forced people around the world to test their stress and ability to connect people and technology in the most dynamic business environment that many of us have ever seen. Organizations quickly experienced actions induced by significant changes in the future of work. The sustainability of those actions will be the real way to recovery. In a post-Covid world, purpose, potential and perspective are, in fact, an improved version of yesterday and a sustainable version of tomorrow. Through its many tools for identifying the emotions that a person affected by a conflict has, focused primarily on the social and relational framework, mediation 
contributes to escalate these feelings and accept a negotiation, by restoring deficient communication. This procedure of mediation has been, is and will be an important architect in promoting and consolidating the practices of democracy, human rights and freedoms, at the international level, which integrates the moral values common to the subjects of law and carries out its mission, focused on the triple commitment of neutrality, impartiality and confidentiality.

\section{REFERENCES}

Bodoni, Cristina. 2016. The Digital Diplomacy and the Romanian Ministry of Foreign Affairs during the period 2010-2016. „Carol I" National Defence University, Bucharest, Strategic Colloquium Journal, no.9. https://cssas.unap.ro

Beillerot, Jacky. 2010. Mediation, education et formation. Trema - international journal of education sciences, no. 23/2004-online. http://journals.openedition.org/trema/572

Charter of the United Nations of 26 June 1945, issuing authority: U.N. 2021. http://www.anr.gov.ro /docs/legislatie/internationala.

Economic Community of West African States. 2008. ECOWAS Conflict Prevention Framework. ECOWAS Commission Publishing House, Abuja.

European Commission. 2012. Mediation, Guidelines of good practices, under the Hague Convention of 25 October 1980, on the civil aspects of international child abduction. HCCH Publishing House (Hague Conference on Private International Law, Standing Bureau), Hague, Netherlands.

Ghiba, Daniel. 2015. Prevention and resolution of international conflicts, Overview. "Carol I" National Defence University Publishing House, Bucharest.

Ghiba, Daniel. 2017. Crisis Management, University Course. „Carol I” National Defence University Publishing House, Bucharest.

Ghiba, Daniel (master's supervisor), Simion, Elena (MSc student). 2020. Mediation-an instrument for conflict resolution. Dissertation „Carol I" National Defence University, Bucharest.

Ghiba, Mădălina-Daniela. 2017. War and armed conflict from an international law perspective, Journal of "Carol I", National Defense University Bucharest, September. https://revista.unap.ro/

Hinds, Georgia. 22 April 2020. What happens when the laws of war meet a pandemic?, The Strategist, Australian Strategic Policy Institute.https:// www.aspistrategist.org.au

Hantz, Nathalie. 16 June 2020. Ho are The Platforms of Amicable Dispute Resoluti On?. Publishing House Village de la Justice, On line publication. https://www.village-justice.com

lordache, Constantin. 2005. Legal resolution of international disputes. „Carol I" National Defence University Publishing House, Bucharest.

International Committee of the Red Cross. 1977. Annexe of 24 June 2009, concerning the putting into practice of the International Health Regulations 2005. Legislative Portal. http://legislatie.just.ro

International Committee of the Red Cross. 2009. Protocol additional no. 1 of 10 June to the Geneva Conventions of 12 August 1949 relating to the Protection of Victims of International Armed Conflicts. Legislative Portal. http://legislatie.just.ro.

OCHA. 2016. Resolution 46/182, wich created the humanitarian system turns twenty-five. http://www.unocha.orgstory

OCHA. 2020. Global Humanitarian Response Plan: COVID-19 (April - December 2020). Appeal Source OCHA. http://reliefweb.int/report

Radu, Răzvan Horaţiu. 2016. European Convention on Human Rights, Course Notes. Juridical Universe Publishing House, Bucharest.

U.E. International health regulation. 2009. The official journal al U.E. https://www.linguee.com 